\title{
Entrañamiento: la experiencia incorporada del espacio arquitectónico cotidiano
}

\section{Intrangement: incorporated experience of everyday architectural space}

\author{
Lucas Javier, Bizzotto ${ }^{1}$ \\ ${ }^{1}$ Universidad Nacional del Litoral, Santa Fe, Argentina \\ 'bizzottoarq@gmail.com / https://orcid.org/0000-0003-4290-8298
}

Recibido el 07 de septiembre de 2021, aprobado el 27 de diciembre de 2021

\begin{abstract}
RESUMEN | Este artículo de investigación examina el microcosmos doméstico con el objetivo de profundizar en las tramas experienciales del espacio cotidiano. El estudio se mueve sobre dos vías fundamentales: la experiencia corporal y el espacio arquitectónico, ambos vinculados a la crítica contemporánea en torno a la noción de experiencia sensible. Se considera que, al extenderse la propiocepción en los espacios cotidianos se facilita la acción corporal al tiempo que se dificulta la reflexión, alterar la percepción es una herramienta para volver a las cosas mismas. Para defender esta hipótesis se desarrolla aquí la explicación fenomenológica de la propiocepción extendida y del proceso de cotidianización (Bégout, 2009). Se aborda, además, la alteración perceptiva desde un posicionamiento de atención a lo infraordinario (Perec, 1973). Metodológicamente el trabajo se precisa como una reflexión teórica. De los resultados se evidencia que indagar en los saberes instaurados, naturalizados y dominados por lo cotidiano constituye un posicionamiento para superar ciertos automatismos proyectuales, pero también, para interpretar los patrones de comportamiento, directamente relacionados con la experiencia corporal afectada por las características del espacio. Finalmente surge la noción de extrañamiento, como alteración que desnaturaliza la percepción del espacio cotidiano y como camino abierto para continuar la investigación, pues guarda el potencial para estimular el proceso de diseño proyectual
\end{abstract}

PALABRAS CLAVE | Cotidianización, espacio cotidiano, experiencia corporal, fenomenología, propiocepción extendida

ABSTRACT | This article seeks to inquire about the experience of everyday space to analyze the domestic microcosm. The study moves along two fundamental paths: the bodily experience and the architectural space both linked to contemporary criticism around the notion of sensible experience. By extending proprioception in everyday space bodily action is facilitated while reflexivity is hindered; then altering perception becomes a tool to get back to things themselves. To support this hypothesis, a phenomenological explanation of the extended proprioception and the process of quotidianization (Bégout, 2009) are both developed here. Furthermore, perceptual alteration from the singular positioning of attention to the infra ordinary (Perec, 1973) is approached. Methodologically the work is specified as a theoretical reflection. The 
results show that inquiry in established and naturalized knowledges dominated by the quotidian constitutes a position to overcome certain project automatisms, but also to interpret the behavior patterns directly related to the bodily experience affected by the characteristics of the space. Finally, the notion of estrangement arises as a perceptual alteration. Further research on this topic could be directed towards estrangement as a stimulus for the development of the project process.

KEYWORD | Bodily experience, process of quotidianization, everyday space, extended proprioception, phenomenology

\section{Introducción}

Plantear la cuestión del espacio doméstico desde la incorporación como fenómeno perceptivo, pero sobre todo, desde la cotidianidad como proceso relacional entre el cuerpo y el espacio, acarrea una serie de conflictos, polisemias ${ }^{1}$ e incluso contradicciones. Justamente en esas indeterminaciones de nociones tan familiares es donde reside la motivación de este estudio. En ese sentido, se construye una mirada situada, inquisitiva y reflexiva frente al espacio cotidiano, para aportar algunos aspectos de la relación entre experiencia corporal y espacio arquitectónico al debate sobre la vivienda.

La idea del espacio arquitectónico como una especie de prótesis que extiende nuestras posibilidades sensibles ya fue, de alguna manera, desarrollada por diversos autores (Norberg-Schulz, 1975; Bloomer y Moore, 1982; Spuybroek, 2008 y Pallasmaa, 2015 entre otros); sin embargo, el consecuente accionar automático e irreflexivo no ha sido suficientemente explorado. Coincidiendo con Perec (2013), estamos tan habituados a lo habitual que se lo deja pasar como si no comunicara nada importante; además, frente a los veloces cambios que trae aparejado el avance de las tecnologías de la comunicación y los medios de transporte, se hace más difícil interrogarlo y describirlo. Se impone así la necesidad de volver a revisar lo aprehendido para resignificar críticamente la disciplina.

Considerar como incorporado al espacio arquitectónico cotidiano, hecho que facilita la acción corporal -por hacerse extensión de nuestra propiocepción- y que paralelamente, dificulta la reflexión acerca de él - por ser tan familiar-, hace entrever algunos puntos esenciales. En particular, el desarrollo de este escrito ha sido trazado precisamente por la naturaleza del objeto estudiado. En el primer apartado se esboza, por tomar un caso del que nadie es ajeno, una aproximación muy breve a la definición de espacio doméstico, para inmediatamente, construir la noción de entrañamiento ${ }^{2}$ como la experiencia corporal resultante de la incorporación de los espacios arquitectónicos; lo relevante de esta sección es la indagación acerca de la concepción fenomenológica de propiocepción extendida ${ }^{3}$. En el segundo apartado, se examina lo cotidiano como un proceso evolutivo y

1 Existen diversas miradas que se construyen alrededor de la noción de espacio doméstico y variedad de significados en diferentes contextos disciplinares, históricos e incluso culturales.

2 En contraposición a la de extrañamiento. Es decir, mientras que lo extraño refiere a novedad, la sorpresa y en cierto sentido a la ignorancia; lo entraño significa llevar dentro, intimidad, estrechez o unión. La experiencia de extrañamiento se ha desarrollado extensamente en: Lucas Bizzotto, "Extrañamiento. La experiencia corporal en el espacio alterado del ex Molino Marconetti", AREA, 26(2) (2020): https://www.area.fadu.uba.ar/area-2602/bizzotto2602/

3 La propiocepción refiere a la consciencia de cada una de las partes de nuestro cuerpo y de la relación entre ellas. Sin embgo, como se verá más adelante, el esquema corporal se extiende al manipular herramientas u objetos externos. Como expresa Merleau-Ponty, éstos dejan de "ser objetos cuyo volumen y tamaño se determinaría por comparación con los demás objetos [para convertirse] en potencias voluminosas" (1984, p. 160). En definitiva el cuerpo se extiende a través de ellos ampliando su horizonte 
se hace referencia, desde esta perspectiva, al interior del espacio doméstico; se desprende aquí la dimensión temporal del espacio arquitectónico. En el tercer apartado, siguiendo las ideas de Perec, se propone el posicionamiento lúdico-reflexivo de atención a lo infraordinario ${ }^{4}$ con la intención fenomenológica de desnaturalizar y volver a las cosas mismas. Finalmente, en el cuarto apartado, se exponen las conclusiones.

\section{Entrañamiento. La experiencia corporal del espacio incorporado}

El espacio doméstico es, quizá por ser el más antiguo, el espacio arquitectónico más estudiado. Desde las esferas de la intimidad se lo ha contrapuesto al espacio público; estar en la privacidad de la casa propia ha constituido en diversos estudios, tanto filosóficos como arquitectónicos, un sitio para la protección, la ensoñación, el resguardo, la tranquilidad y la seguridad. Ahora bien ¿por qué indagar en algo que, aparentemente, no nos plantea ningún problema? Dejar de reflexionar más allá de estos conocimientos adquiridos y naturalizados, resulta un reduccionismo ciego o un estancamiento del saber. Sin embargo, la idea no es preguntarse qué significa espacio doméstico o cuáles son sus implicancias intimistas, sino cómo reconocer el espacio arquitectónico tal como nuestro cuerpo lo experimenta, es decir, como una concreción de intimidad. Entregamos el cuerpo a la cotidiana manifestación del espacio doméstico, i.e. a un modo particular de habitar.

El espacio, como el cuerpo, es un horizonte abierto de posibilidades experienciales, en relación con esto, aunque haciendo referencia al objeto, Merleau-Ponty (1984) expresa: “...no se determina más que como ser identificable a través de una serie abierta de experiencias posibles, y no existe más que para un sujeto que opere esta identificación"( p. 228). La pregunta es: ¿reconocemos la totalidad de posibilidades experienciales que ofrece dicha serie? Es decir, ¿experimentamos creativamente los objetos y los espacios? Aquí, vale recordar el conjunto de imágenes que Bruno Munari utilizó para expresar la "Ricerca della comodità in una poltrona scomoda", pero en un sentido de búsqueda perceptiva, de la potencia que guarda un objeto (sillón) para utilizarlo, que no es más que la relación que establecemos con él.

Figura 1. Posibles modos de usar un sillón

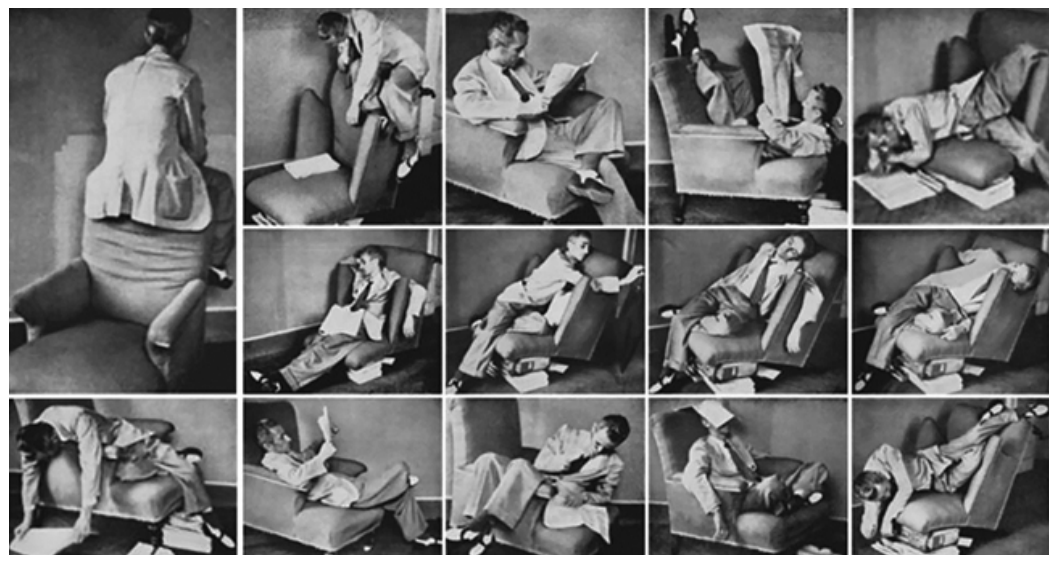

de posibilidades.

4 Perec presenta lo infraordinario en ¿Aproximaciones a qué? (Cause commune, n5, febrero de 1973, pp. 3-4) como parte de una lista acerca de "Lo que ocurre cada día, lo trivial, lo cotidiano, lo evidente, lo común, [...], el ruido de fondo, lo habitual". Aquí sirve como catalizador, para revisitar cualidades naturalizadas del espacio.

5 Bruno Munari, "Búsqueda de la comodidad en una silla incómoda". Revista Domus 202, 1944. Imagen original recuperada de https://www.domusweb.it/it/dall-archivio/2012/03/31/ricerca-della-comodita-in-una-poltrona-scomoda.html con edición propia. 
De este modo, se intentará vislumbrar un aspecto de la connaturalidad ${ }^{6}$ cuerpo-espacio (en tanto se enlazan con tal solidaridad que se vuelven uno, se contagian y asisten) en la experiencia corporal del espacio doméstico como campo perceptivo. La experiencia perceptiva, inherente al ser humano y relación de cada persona con el mundo, puede ser de naturaleza reflexiva o irreflexiva; la primera, lejos de operar como un estímulo respuesta, como un espejo que nos devuelve lo mismo transformado en representación o imagen en el que surge el reconocimiento, funciona como un prisma que abre esa experiencia a otras experiencias y aprendizajes, no devuelve sino que atraviesa. En este orden de ideas, la segunda, corresponde a un modo experiencial en el que se extiende el repertorio sensible corporal por medio de la arquitectura, como dimensión espacial y ésta, a su vez, es aprehendida efectivamente, por la acción de nuestro cuerpo; esto es, lo que aquí se considera como entrañamiento.

Con los espacios conocidos, habituales, cotidianos, se concreta una relación de incorporación mutua, a tal punto que podríamos considerar a ese espacio arquitectónico una extensión de nuestro cuerpo. Es decir que el espacio doméstico, como la segunda (o tercera, si consideramos las vestimentas) corporalidad, se hace coextensivo con el cuerpo que, urdiendo una trama relacional en la experiencia, se articula con los objetos y las estructuras que lo componen. Cada sentido del cuerpo se da como materia y momento de una situación particular que constituye su propio espacio, aunque coexisten y colaboran con la construcción de una configuración global que los abarca; en otras palabras, la unidad del espacio se da en la experiencia corporal como engranaje de sus sentidos. Si, volviendo a Merleau-Ponty (1984), "La cosa y el mundo me son dados con las partes de mi cuerpo (...) en una conexión viva comparable, o más bien idéntica, con lo que existe entre las partes de mi cuerpo" (pp. 220, 221), resulta significativo revisar la noción de propiocepción extendida desde la fenomenología.

Para abordar una definición de extensión propioceptiva que no se reduzca a una articulación estática entre el cuerpo y un objeto externo, es necesario referirse antes al esquema corporal. Para Merleau-Ponty (1984), es el resultado en constante actualización del modo de relacionarnos con el mundo; en este dinámico proceso en espiral, debe darse "una toma de consciencia global de mi postura en el mundo intersensorial" (p. 116) que, lejos de asociarse por superposición de imágenes, se establece como un conjunto de relaciones (¿correspondencias?) que va de lo general a lo particular. En el espacio, el cuerpo se sitúa como espacio propio envuelto del primero y como punto cero de la acción ${ }^{7}$. El esquema corporal se expresa como un complejo entrelazamiento experiencial con el mundo, a través del sentido de orientación y posición en el espacio y de las partes del cuerpo entre sí, esto es, la propiocepción. Entonces, la propiocepción extendida es la amplificación del esquema corporal a partir de utilizar una herramienta o manipular algún objeto externo al cuerpo, nuestra percepción es transferida invisible a través de ellos.

Cuando Merleau-Ponty introduce este concepto, cita dos casos bien conocidos: la extensión del tacto a través del bastón, utilizado por las personas no videntes, que incrementa el alcance sensible y posibilita la interpretación de las diferentes texturas y accidentes en el plano del suelo; o el caso del automovilista que no necesita bajarse a medir en cada situación de pasaje entre obstáculos, sino que las dimensiones del cuerpo se extienden abarcando las dimensiones del automóvil. Al

6 Se hace referencia aquí a la situación particular del sujeto de la sensación que "no es ni un pensador que nota una cualidad, ni un medio inerte por ella afectado o modificado; es una potencia que co-nace (co-noce) a un cierto medio de existencia o se sincroniza con él." (Merleau-Ponty, 1984, p. 227). Cuerpo y espacio arquitectónico, en este sentido, coinciden en una sola naturaleza.

7 En el cuerpo existe, de manera simétrica, un sujeto de la experiencia y un territorio experienciable. Se deja entrever la idea de Leib y Körper, i.e. el cuerpo propio y el cuerpo natural respectivamente. 
referenciar su situación espacial particular, el autor expresa: “Cuando me desplazo en mi casa, sé ya, sin ningún discurso, que ir al cuarto de baño significa pasar cerca de la habitación, que mirar a la ventana significa tener la chimenea a mi izquierda, y en este pequeño mundo, cada gesto, cada percepción, se sitúa inmediatamente respecto de mil coordenadas virtuales" (Merleau-Ponty, 1984, p. 164). En el orden de estas ideas, es factible argumentar que nuestra propiocepción se extiende al espacio arquitectónico, en sentido de lugar propio, de resguardo, de relación con otro exterior, de comunicación e identidad; una especie de trama conjunta que, de manera cambiante, reconoce las partes de la casa constituyendo un espacio encarnado o incorporado.

Antes de emprender cualquier acción, es necesario realizar un reconocimiento formal del espacio o de los objetos con los que se interactúa. La percepción y el objeto se forman al interior de la experiencia corporal y éste responde en acciones, "[mi cuerpo], puesto que se mueve, tiene las cosas en círculo alrededor de sí, ellas son un anexo o una prolongación de él mismo, están incrustadas en su carne, forman parte de su definición plena y el mundo está hecho con la misma tela del cuerpo" (Merleau-Ponty, 1986, p. 17). El cuerpo, al actuar en un contexto espacial determinado, constituye el primer marco referencial del reconocimiento perceptivo. Todos los objetos en el espacio y el espacio mismo están a disposición en la experiencia corporal de entrañamiento. Reconocemos, sin necesidad alguna de ir a comprobar, las partes y la conexión de cada segmento del espacio doméstico, como si nuestro cuerpo fuera un puerto al que arriban, de manera virtual o real, desde diferentes sitios de ese espacio, imágenes, sonidos, olores, estados singulares, entre otros.

Hasta aquí se ha realizado una aproximación al espacio doméstico como espacio incorporado, en su faz de una experiencia de propiocepción extendida o, como se ha propuesto aquí, de entrañamiento. Ahora bien, el espacio doméstico como espacio cotidiano, se vive, principalmente, a partir de la repetición en tanto progresión armónica que conserva regularmente el mismo orden. $\mathrm{Si}$, como expresa Saer (1982), a una palabra cualquiera "Empezamos, curiosos, a repetirla; pero el sentido, que nos fuera tan palmario, no vuelve a pesar de la repetición sino que, por el contrario, cuanto más repetimos la palabra más extraña y desconocida nos suena" (p. 17); el espacio, en ese proceso de habitar cotidiano ¿no pierde también su sentido?, ¿no rehúye a la reflexión al darse todo por sobreentendido?

\section{La dimensión cotidiana del espacio arquitectónico}

El espacio doméstico, desde una dimensión cotidiana e intimista ha sido, en general, poco atendido y estudiado. Existe un vacío reflexivo acerca de lo cotidiano en las teorías de la arquitectura. Dicho hiato reflexivo, desde el posicionamiento de este estudio, se debe a una cuestión perceptiva: el tejido sensible del espacio doméstico, como manifestación más relevante de la dimensión cotidiana del espacio, precisamente por estar atravesado por esta última, tiende a darse por obvio y a pasar desapercibido. En este planteo, el acto de habitar juega un papel esencial; por una parte, relacionado a lo cotidiano como proceso, la acción reiterada se dirige a la incorporación de un hábito, es decir que forja una manera habitual de actuar o comportarse. Por otra, en función de la incorporación de un espacio, como "un medio fundamental en que uno se relaciona con el mundo. Es fundamentalmente un intercambio y una extensión" (Pallasmaa, 2016, p. 7). Habitar es subjetivar el espacio, es hacerlo propio y habitual, es aquello que es sentido como la experiencia en la que se vinculan íntimamente el sujeto de la percepción (Merleau-Ponty, 1984) y esos espacios que se perciben.

Ahora bien, repetir los mismos espacios es un modo de habitar que monta mecanismos silenci- 
osos de rítmicas iteraciones. Las mismas acciones, los mismos cuerpos y los mismos espacios se relacionan, la mayoría de las veces, de la misma manera. Estos mecanismos son parte de un "proceso de cotidianización" (Bégout, 2009, p. 13) del espacio que, a la vez que facilita la experiencia de entrañamiento como relación protésica entre cuerpo y espacio arquitectónico, lo naturaliza y da por obvio a tal punto que dificulta su reflexión. En efecto, "la vida cotidiana no es un simple estado de cosas claro y transparente: esa presencia masiva, repetitiva, omnipresente de la satisfacción de las necesidades elementales a través del sesgo de actividades comunes (comer, trabajar, dormir, vestirse, etc.)" (Bégout, 2009, p. 12). La repetición refuerza la trama de relaciones orgánicas entre el sujeto y el espacio habitado que tienden a perseverar. Todo lo que aparece, lo que se muestra, pierde su cualidad de indicio para comportarse como aspecto de ese espacio. Con esto se quiere señalar que esa relación ambivalente que establecemos con el espacio, pasa de presentar (como indicio) un abanico de respuestas posibles a (como aspecto) una respuesta naturalizada. En otras palabras se transita un proceso que va de la posibilidad a la certeza.

Siguiendo a Bégout, "todo lo que es cotidiano se vuelve familiar y ordinario, incluso banal. Pero se trata entonces de efectos secundarios de la experiencia cotidiana, no de sus causas primeras" (Bégout, 2009, p. 12); probablemente una causa sea, como expresa Valery, que por lo general "nuestras percepciones suscitan en nosotros, cuando suscitan algo, aquello que se precisa para anularlas o al menos intentarlo. Ya mediante un acto, reflejo o no, ya por una especie de indiferencia, adquirida o no, las cancelamos o lo intentamos" (Valéry, 1999, p. 189). En definitiva, al sustentarse en la confianza de experiencias pasadas, al habitar como una metáfora constante, se dificulta la reflexión, pues no se plantea una inquietud o un cuestionamiento.

Es evidente que la dimensión temporal ${ }^{8}$ del espacio cumple un rol fundamental en la experiencia doméstica, sobre todo al considerar lo cotidiano como un proceso. Pallasmaa (2016, p. 114), en ese sentido afirma que, la obra arquitectónica, frente a la inconmensurabilidad del universo, constituye una medida humana del espacio y del tiempo. Los atributos de la escala espacio-temporal de una obra arquitectónica son, entonces, un medio que da sentido a la experiencia corporal. El espacio arquitectónico reproduce un tiempo específico en él, que refleja las relaciones sociales de un momento histórico de la humanidad, pero está, además, dominada por diferentes ritmos, desde los propuestos a partir del proyecto por medio de diferentes representaciones formales estáticas (la sintaxis, los agrupamientos y las substancias formales), hasta los ritmos vitales de su habitabilidad. El cuerpo que se desplaza es un cuerpo que se mueve, el movimiento incorporado relaciona espacio, tiempo y cuerpo en el acto. En la experiencia de movimiento, el espacio opera como una extensión mientras que el tiempo, en tanto, como acaecimiento de sucesos o acciones, es decir, un proceso.

La arquitectura doméstica que habitamos cotidianamente es parte entrañable de nuestra existencia, está internalizada en nuestras acciones corporales, nos ocupa como nosotros a ella. Sin embargo, la experiencia del espacio vivido, lejos está de ser un espacio homogéneo, por el contrario, es un espacio fragmentado, con fisuras, donde algunas partes son significativamente diferentes en cuanto a lo cualitativo. Lo cotidiano tiende a alisar la profundidad sensible de la experiencia y, con igual paso, el cuerpo aprehende aquello que alguna vez le fue extraño (en el caso del espacio arquitectónico este proceso es recíproco); dicho de otra manera, mientras el cuerpo se acostumbra al espacio, éste tiende a formar parte de él, y esta relación facilita las acciones pero convierte al prim-

8 Tanto las ideas como las experiencias temporales en la teoría de la arquitectura han sido superadas por las del espacio. Sin embargo, puede interpretarse la incorporación de diferentes nociones de dimensiones temporales en Giedion (1941) o Zevi (1951) y en más recientes, focalizados en aspectos perceptivos, Moore y Allen (1976) Moore y Bloomer (1977), Pallasmaa (2012, 2014, 2015), Holl (1997, 2011), Zumthor (2006). 
ero en una especie de autómata. Resulta paradójico que, lejos de casa, esos aspectos del espacio cotidiano, a los que no prestamos atención, son los que vuelven con nostalgia en olores, sabores, texturas o situaciones.

En síntesis, definitivamente lo cotidiano es opuesto al estado incierto de lo extraño y, por consiguiente se infiere que: desde lo analítico, dado que lo cotidiano no es algo tangible, se debería reflexionar acerca del modo en que se manifiesta, y para ello se hace necesario un posicionamiento perceptivo diferente, alterado frente al espacio cotidiano; y desde lo propositivo (como diseñadores), alterar la morfología del espacio, permitir, o mejor dicho, provocar la mutabilidad virtual o real de ese espacio, puede convertirse en una herramienta proyectual. Si bien, siguiendo a Bégout: "En tanto que asentamiento mudo de toda experiencia, lo cotidiano posee una densidad genética notable, una estabilidad y tenacidad durables, algo que resiste de veras" (Bégout, 2009, p. 18); existe algo en las propiedades de las cosas que le dan carácter al espacio arquitectónico: los colores, los materiales, las texturas, los cambios de éstos con el movimiento de la fuente de luz, los olores, incluso las partes constructivas implícitas (aquello oculto o que no existe, lo que debió usarse y quitarse para su materialización), los indicios, las señales de uso, entre otras que, en conjunto, componen un sistema mutable posible de reconocer a través de un posicionamiento perceptivo singular.

\section{La atención a lo infraordinario9 como posicionamiento lúdico-reflexivo}

Lo cotidiano ha sido ampliamente considerado, sin su justa profundización, como trivial, normal, insignificante, ordinario; aquí es donde cobra valor la imagen poética de lo cotidiano. Georges Perec, en Especie de espacios (1974), Tentativas de agotar un lugar parisino (1975) o en la película Un hombre que duerme (1974) -en la que participó como guionista y codirector junto a Bernard Queysanne- ha colocado lo habitual, lo obvio y ordinario en el centro de interés; con un esfuerzo perceptivo, descubre las presencias omitidas por efecto de la repetición y, una vez reconocidas, las atraviesa. A continuación, se realiza una aproximación interrogativa a la cotidianidad del espacio doméstico, sustentada en ese particular posicionamiento curioso frente a, como diría Perec, lo infraordinario.

Una vez incorporado, el espacio doméstico deja de producir la inquietud inicial, cuando todo era potencialidad; la conquista de la tranquilidad en estos espacios y la acción repetida y automática, se contraponen a la turbación estimulante que produce el encuentro con lo desconocido. La idea es "interrogar, sea el ladrillo, el hormigón, el vidrio, nuestros modales en la mesa, nuestros utensilios, nuestras herramientas, nuestros horarios, nuestros ritmos. Interrogar aquello que parece haber dejado de sorprendernos" (Perec, 2013, p. 15), en este punto resulta tentador retornar al origen, entonces, a una experiencia de extrañamiento, y esto tiene que ver con un aspecto central de la fenomenología: la epojé. Es volver a las cosas mismas mediante el ir atrás, el develamiento de capas sucesivas de representaciones que las ciencias han colocado sobre lo sensible. De alguna manera, ese ocultamiento lo expresa Cortázar, cuando en una carta, citando a Rilke, escribe: "Y esto se llama perro, y eso se llama casa... Vosotros, con vuestros nombres, estáis matando las cosas" (Cortázar, 2012, p. 71), es decir, cubriéndolas de prejuicios.

La fenomenología, entonces, explica las cosas a partir de interrumpir el curso natural y detenerse

9 El estudio de Vallespín, Suárez, \& De La Rosa, (2019) propone un acercamiento al pasaje de lo infraordinario a lo extraordinario a través del dibujo. Allí consideran que lo cotidiano, "en cuanto que espacio de lo extraño, se escapa siempre como lo más difícil de descubrir" (p. 211) y, desde ese enfoque, representar lo infraordinario, como un acto de extrañamiento, hace significante lo insignificante, resquebraja lo cotidiano, lo hace aflorar (p. 215). 
a observar. Esa actitud, en el espacio doméstico, es prácticamente un juego. Ser paciente como un pescador nocturno, estar atento a las diferencias, ir lento, detenerse, percibir, dejarse derivar por la geografía de lo íntimo (¿una psicogeografía ${ }^{10}$ doméstica?). Alterar la percepción a partir de dilatar el movimiento, extender el tiempo, detenerse y suspender las respuestas para observar a través de aquellos intersticios inexplorados, una especie de introspección dirigida paradójicamente hacia fuera -al interior del espacio doméstico- para captar corporalmente la experiencia cambiante del espacio. Imprimir lentitud a la acción corporal en el espacio arquitectónico es un juego perceptivo para disminuir lo extraordinario del sentido de la vista, borrar las distancias y alcanzar lo táctil. Una verdadera actitud perceptiva de resistencia a los embates de la velocidad y de la instantaneidad ${ }^{11}$.

En el orden de lo artístico, entre lo real y lo fantástico, Abel Monasterolo da cuenta de la necesidad de seguridad en el espacio doméstico, pero sugiere, a la vez, la posibilidad (o quizás también sea necesidad) de entrar y sumergirse en un mundo de sorpresas insospechadas que alteren lo cotidiano. Exteriormente, los elementos de una potencial (¿mágica?) arquitectura de monte se materializan; su forma es fácilmente aprehensible y toda la ornamentación celebra la puerta de entrada, como una invitación o tentación a abrir y explorar. En el interior, por el contrario, el espacio arquitectónico se horada, las entrañas del lugar propio, de lo familiar y lo cotidiano se puebla de seres (acontecimientos) extraños que convocan a la intemporalidad, se expande la percepción (imaginación) a partir del juego de superposición con diferentes planos y escalas. Parece abrirse un exterior por dentro y cerrarse al interior por fuera. Ciertamente, ésta es una interpretación subjetiva de un objeto singularmente evocador y metafórico, donde lo anómalo se instala en lo cotidiano.

Figura 2. De la serie «Monte» del año 2020 madera policromada

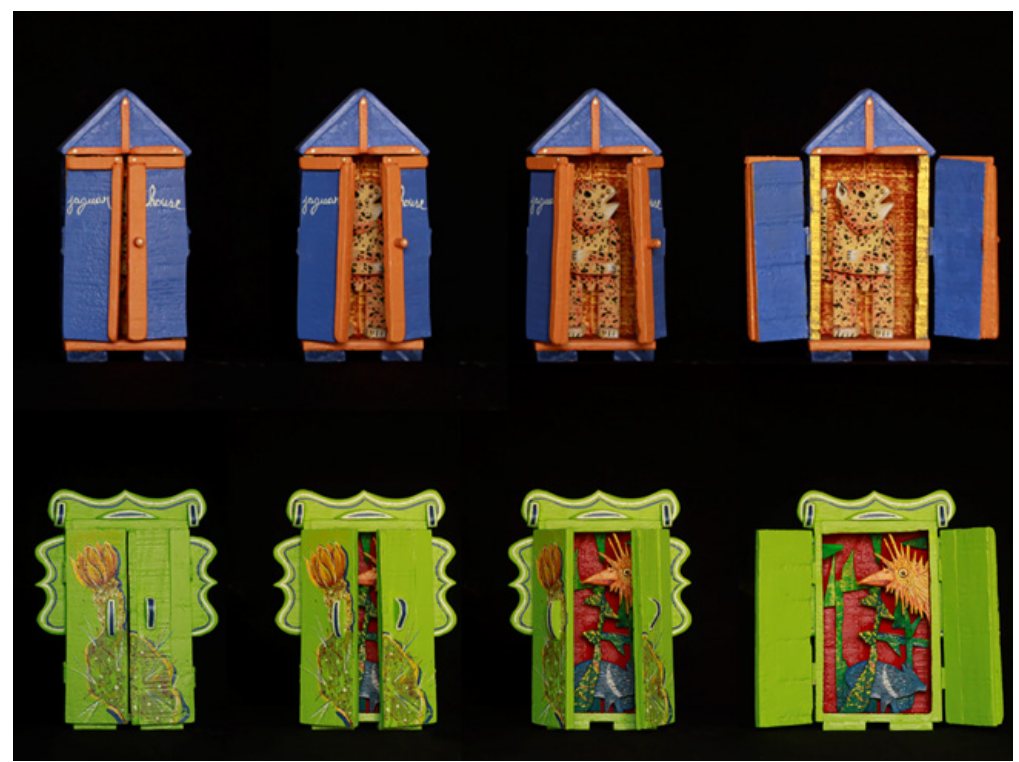

Nota. Elaboración propia. https://youtu.be/MoQQK8-Pd-o (Video realizado con imágenes propias de la obra del artista y sonidos ambientes del Litoral santafesino).

10 ¿Es posible una psicogeografía doméstica? La noción de la Internacional Situacionista que hace referencia, sintéticamente, a la relación entre las emociones de un sujeto y el espacio en el que se encuentra (urbano por lo general), está ligado a la teoría de la deriva (1958) de Guy Debord. Una psicogeografía doméstica implicaría, en esta búsqueda por comprender un espacio íntimo y único, los efectos psíquicos que produce la vivienda con sus formas y los comportamientos que allí se dan.

11 Parte de la investigación en curso estudia la práctica disciplinar del dibujo a mano alzada como resistencia sensible frente a la velocidad del avance tecnológico. La misma se centra en el análisis y la caracterización de la cognición involucrada en el acto de dibujar el espacio arquitectónico construido. 


\section{Reflexiones finales}

Se ha intentado, en este breve recorrido, plantear un modo habitual de habitar el espacio arquitectónico, el cotidiano espacio doméstico, desde la experiencia corporal que aquí se llamó entrañamiento. Para probar que dicho entrañamiento, a la vez que facilita el accionar corporal dificulta la reflexión en/de los espacios arquitectónicos incorporados; se mostró, desde una base fenomenológica, cómo es posible considerar al espacio arquitectónico extensión propioceptiva de nuestro esquema corporal; y se revisó la idea de lo cotidiano como un proceso de naturalización que tiende a ocultar lo sensible. Además, a partir de un posicionamiento singular de atención a lo infraordinario, se pudo inferir que, frente a la hermeticidad del espacio cotidiano, alterar la percepción se convierte en una herramienta analítica y propositiva para estimular los sentidos, lo que supone constituir un posible camino para volver a las cosas mismas.

En otras palabras, los espacios que habitamos habitualmente, a partir de un proceso de cotidianización, se hacen carne de nuestra carne y se cubren de una naturalidad irreflexiva. La inteligencia tiende a repetir lo conocido, la experiencia se torna experiencia de otras experiencias pasadas. Para escapar de esta repetición e incorporar novedad a lo existente, a lo naturalmente aprehendido, la atención a lo infraordinario se convierte en una herramienta de alteración perceptiva que transforma esa experiencia sensible en algo significativo. De lo expuesto se deriva que indagar en saberes instaurados, naturalizados y dominados por lo cotidiano, como el espacio doméstico, constituye un posicionamiento para superar ciertos automatismos proyectuales (esto es repetir, no sin cierta actitud acrítica, las mismas tipologías, composiciones o cualidades formales frente a diferentes problemas arquitectónicos), pero también, para interpretar los patrones de comportamiento directamente relacionados con el cuerpo en el espacio (movimientos o desplazamientos habituales que se vuelven previsibles). Como consecuencia, surge un nuevo camino para explorar, relacionado con la posibilidad de considerar al extrañamiento como herramienta propositiva de provocación intencionada que alerta/altera los sentidos.

Aunque lo cotidiano inexorablemente se reconstituya, el posicionamiento perceptivo atento al detalle y a los sutiles cambios, el juego provocativo de alterar la experiencia corporal o el proyectar centrados en la vivencia de los sujetos, conserva, al menos, una intención crítica frente a lo fuertemente naturalizado, sedimentado de costumbres, hábitos y representaciones. De alguna manera, concebir espacios arquitectónicos alterados, induce una serie de acontecimientos que perturban lo habitual, provocan un paso lento que dilata el tiempo, obligan a detener los automatismos y, consecuentemente, propician el cuestionamiento, la reflexión crítica y una reformulación trascendental de lo aprehendido.

\section{Referencias}

Allen, G., \& Moore, C. W. (1978). Dimensiones de la arquitectura. Espacio, forma y escala. (P. Bonet \& E. Riambau i saurí, Trads.), 1976. Barcelona: Gustavo Gili.

Bégout, B. (2009). La potencia discreta de lo cotidiano. Persona y Sociedad, XXIII(1), 09-20. https://doi.org/https://doi.org/10.11565/pys.v23i1.172.

Bloomer, K. C., \& Moore, C. W. (1982). Cuerpo, memoria y arquitectura. Introducción al diseño arquitectónico. (M. T. Muñoz Jiménez, Trad.), 1977. Madrid: H. Blume.

Giedion, S. (2009). Espacio, tiempo y arquitectura: origen y desarrollo de una nueva tradición. (J. Sainz, Trad.), 1941. Barcelona: Reverté.

E-ISSN: 2518-2943 | WEB: www.camjol.info/index.php/arquitectura| DOI: https://doi.org/10.5377/arquitectura.v6i12.12323 | E-MAIL: rvarqui.mas@farq.uni.edu.ni 
Holl, S. (1997). Entrelazamientos. (G. Bohigas, Trad.), 1996. Barcelona: Gustavo Gili.

Holl, S. (2011). Cuestiones de Percepción. Fenomenología de la arquitectura. (M. Puente, Trad.), 1994. Barcelona: Gustavo Gili.

Merleau-Ponty, M. (1984). Fenomenología De la Percepción. (J. Cabanes, Trad.), 1945. Barcelona: Planeta-Agostini.

Merleau-Ponty, M. (1986). El ojo y el espíritu. (J. Romero Brest, Trad.), 1964. Barcelona: Paidòs Ibérica.

Norberg-Schulz, C. (1975). Existencia, espacio y arquitectura. (A. Margarit, Trad.), 1971. Barcelona: Editorial Blume.

Pallasmaa, J. (2012). La mano que piensa. Sabiduría existencial y corporal en la arquitectura. (M. Puente, Trad.), 2009. Barcelona: Gustavo Gili.

Pallasmaa, J. (2014). La imagen corpórea. Imaginación e imaginario en la arquitectura. (C. Muro, Trad.). Barcelona: Gustavo Gili.

Pallasmaa, J. (2015). Los ojos de la piel. La arquitectura y los sentidos. (M. Puente \& C. Muro, Trads.) (2.a ed.). Barcelona: Gustavo Gili.

Pallasmaa, J. (2016). Habitar. (Á. Giménez Imiriazaldu, Trad.). Barcelona: Gustavo Gili.

Perec, G. (2013). Lo infraordinario. (F. Jorge, Trad.), 1989 (1.a ed.). Madrid: Eterna Cadencia.

Spuybroek, L. (2008). The architecture of continuity. Rotterdam: V2_ / NAi Publishing.

Valéry, P. (1999). Piezas sobre el arte. (J. L. Arántegui, Trad.), 1960. Madrid: Visor.

Vallespín, N., Suárez, E. S., \& De La Rosa, C. V. (2019). From the infraordinary to the extraordinary. Outlines of an architectural conceptualisation. EGA Revista de Expresion Grafica Arquitectonica, 24(36), 210-221. https://doi.org/10.4995/ega.2019.11301

Zevi, B. (1963). Saber ver la arquitectura. (C. Calcaprina \& J. Bermejo Goday, Trads.), 1951 (4.a ed.). Buenos Aires: Poseidón.

Zumthor, P. (2006). Atmósferas. (P. Madrigal, Trad.). Barcelona: Gustavo Gili. 